\title{
Preoperative Multi-Detector Computed Tomography in Kidney Donors; Quantitative Data Report from Operation Rooms
}

\author{
Nariman Nezami ${ }^{1,2}$, Mohammad Naghavi-Behzad ${ }^{3,4,5}$, Reza Piri $^{3,4,{ }^{*}}$, Behzad Salari $^{6}$, Steve Hool $^{1}$, \\ Mohammad Khalid Mojadidi ${ }^{7}$, Sona Ghorashi ${ }^{8}$, Mohammad Kazem Tarzamni ${ }^{2}$ and Bijan Bijan ${ }^{9}$ \\ ${ }^{1}$ Department of Radiology and Biomedical Imaging, Yale University School of Medicine, New Haven, USA \\ ${ }^{2}$ Department of Radiology, Tabriz University of Medical Sciences, Tabriz, Iran \\ ${ }^{3}$ Medical Philosophy and History Research Center, Tabriz University of Medical Sciences, Tabriz, Iran \\ ${ }^{4}$ Department of Nuclear Medicine, Odense University Hospital, Odense, Denmark \\ ${ }^{5}$ Students' Research Committee, Tabriz University of Medical Sciences, Tabriz, Iran \\ ${ }^{6}$ Department of Medicine, School of Medicine, Harvard University, Boston, USA \\ ${ }^{7}$ Division of Cardiology, Department of Medicine, University of Florida College of Medicine, Gainesville, USA \\ ${ }^{8}$ Young Researchers Club, Tabriz Branch, Islamic Azad University, Tabriz, Iran \\ ${ }^{9}$ Department of Diagnostic Radiology and Nuclear Medicine, University of California Davis Medical Center, Sacramento, USA \\ "Corresponding author: Reza Piri, Medical Philosophy and History Research Center, Tabriz University of Medical Sciences, Tabriz, Iran. Tel: +98-9141198967, E-mail: \\ dr.reza.piri@gmail.com
}

Received 2017 August 05; Revised 2018 February 19; Accepted 2018 February 22.

\begin{abstract}
Background: Multi-detector computed tomography (MDCT) angiography is a non-invasive imaging modality, and is replacing the invasive conventional angiography in preoperative studies of vascular anatomy.

Objectives: To determine the accuracy of MDCT in diagnosis of the renal arterial and venous anatomy, urinary collecting system and kidney anatomy itself in living kidney donors.

Patients and Methods: In the present prospective single-center study, 134 potential kidney donors (age: $25.65 \pm 3.37$ years) underwent MDCT and MDCT angiography in a single center (Aug 2012 - Oct 2013). The bolus tracking method was used. Arterial and venous anatomical variations and kidney size were assessed and compared with the surgical findings.

Results: MDCT angiography revealed renal arteries, their branching with $100 \%$ sensitivity, specificity, positive and negative predictive values. In addition, the sensitivity, specificity, positive predictive value and negative predictive value for MDCT angiography were $85.71 \%, 100 \%, 100 \%$ and $99.14 \%$, respectively, in diagnosis of venous branching pattern. There is direct linear correlation between MDCT angiography and surgical findings in measuring arterial length and diameter, and kidney size (All P values $<0.001$ ). Only one patient had ureteral duplication.

Conclusion: MDCT determines the renal vascular and urinary collecting system anatomy, and kidney characteristics with almost $100 \%$ accuracy in kidney donors.
\end{abstract}

Keywords: Computed Tomography, Angiography, Kidney, Artery

\section{Background}

Renal vasculature anatomy plays a major role in the selection of renal donors (1). In the process of enrolling the appropriate donor, the accuracy of the chosen radiologic technique in assessing renal vascular anatomy of donors is crucial for the kidney harvesting plane (2-5), since the presence of renal accessory vessels, early branching or multiple veins may become a challenge for transplant surgeons and could result in complication and eventually transplant failure (1).

Conventional angiography was traditionally used as the golden standard for determining anatomy and final preoperative anatomy/planning of kidney donation. Recent advances in safe and less/non-invasive imaging technology have led transplant surgeons to evaluate multidetector computed tomographic angiography(MDCT) and magnetic resonance angiography (MRA). MDCT angiography is a useful non-invasive imaging modality, and is widely used instead of invasive conventional angiography in preoperative studies of body vasculature. Recent renal MR and CT imaging studies have reported good but variable correlation with conventional angiography, depending on the technique used (6-8). 


\section{Objectives}

To compare the preoperative 64 MDCT angiography and intraoperative surgical findings in living kidney donors regarding renal arterial and venous anatomy, urinary collecting system and kidney anatomy, which is quite novel compared to previously reported results using laparoscopic methods.

\section{Patients and Methods}

\subsection{Study Design}

During the current prospective study from August 2012 to October 2013 renal MDCT and surgical findings of 134 potential kidney donors were evaluated.

The study protocol was approved by the ethics committee of Tabriz University of Medical Sciences and in compliance with the Helsinki declaration. The participants signed an informed written consent form to allow the researchers to collect the acquired data for the current study.

\subsection{Study Population}

The study population was composed of consecutively scanned potential kidney donors who underwent renal MDCT at our hospital as in the study period part of pretransplant screening evaluation and later underwent kidney harvesting. Inclusion criteria were as follows: no hypersensitivity to contrast materials, no pathologic or abnormal vascular or renal finding, complicated anatomical variation of vascular or urinary collecting systems on MDCT study, accepted donation before surgery, and gave consent for kidney harvesting. Subjects with abnormal renal function and any of the following major variations in renal vascular anatomy affecting kidney donation on MDCT evaluation were excluded: presence of major accessory artery (duplicated main renal artery), hilar renal accessory artery, primary renal artery branching, more than one accessory artery, and major renal venous anomalies e.g. circumaortic renal vein, late venous confluence, accessory renal vein, and retro-aortic renal vein.

\subsection{CT Scan Protocol}

Unenhanced CT images were obtained, followed by arterial, venous and delayed series of contrast-enhanced images. Cases were asked to drink water, at least $500 \mathrm{~mL}$ during 30 minutes till the beginning of the exam and then $120 \mathrm{~mL}$ just before the exam. Then, non-enhanced MDCT exam was performed. Then, iopromide $300 \mathrm{mg} / \mathrm{mL}$ at the rate of 4 - $5 \mathrm{~mL} / \mathrm{s}$ (Ultravist 300, Schering, Germany; dosing of $1.5 \mathrm{~mL} / \mathrm{kg}$ up to maximum $120 \mathrm{~mL}$ ) was injected into the donor, followed by a $40 \mathrm{~mL}$ normal saline bolus chase using a dual-head pressure injector (Medrad, USA). Multiplanar reconstructions were used to produce coronal and sagittal images by producing perspectives at right angles to a load of transverse slices.

\subsection{Images Analysis}

The image volumes were reconstructed at $1 \mathrm{~mm}$ slice thickness and 50\% overlap for the arterial phase. The evaluated parameters included: 1 ) the length of the main renal artery (from branching to the ostium), 2) the diameter of the main renal artery at emergence from the aorta, 3) the existence and number of accessory arteries, 4) the existence of any early branching (any artery branch arising within $1.5 \mathrm{~cm}$ of the ostium for the left renal artery and 2.5 $\mathrm{cm}$ of the ostium for the right renal artery, 5) the kidney width, length and anteroposterior diameter (APD), 6) venous multiplicity and variations, and 7) Variations in the urinary collection system.

Image quality was categorized into three groups scaled from 0 to 2. 0 , poor vascular or urinary collecting system visualization with noise and/or artifact resulting in nondiagnostic and non-interpretable image; 1 , adequate vascular and urinary collecting system visualization with artifact and/or noise that does not interfere with interpretation; 2, good vascular and urinary collecting system visualization with nearly no noise and/or artifact resulting in a confident interpretation. While image qualities of 1 or 2 were considered diagnostic, images qualified as 0 were excluded from the study.

\subsection{Surgical Evaluation}

Two transplant surgeons evaluated the cases during the harvesting procedure. One of the surgeons was blinded to the MDCT findings and performed all measurements. All cases underwent open laparotomy. Vascular diameters were measured before ligation and harvesting. A handheld 500-197-20 digital caliper (Mitutoyo, Tokyo, Japan) was used for measurement during operation. The renal artery size was measured from the renal artery ostium to the location of renal artery branches. The kidney length was defined as the distance between the upper and lower apex of the kidney. The kidney width was defined as the longest trans-axial renal diameter.

\subsection{Statistical Analysis}

Data analysis was performed using SPSS software package v13.0 (SPSS Ins., Chicago, USA). The results are presented as mean \pm standard deviation (SD). The inter-group statistical significance was determined using the independent 
sample t-test and the Fisher exact test. The correlation was studied using the Pearson correlation test. The interobserver variation (agreement level between the readers) was studied by Cohen $\kappa$ values. The results with P value $<$ 0.05 were considered significant.

\section{Results}

Finally, the MDCT images and intraoperative assessments were completed for 123 subjects, after exclusion of three subjects due to non-diagnostic image quality (due to motion artifact) and eight cases because of cancellation of the donation (three cases due to complicated anatomical variations, four cases refused donation, and one discovered to have hypertension in later clinical evaluation). Then, surgical evaluation of 123 harvested kidneys were compared with MDCT findings of corresponding kidneys.

Eighty-seven (70.7\%) of the subjects were male and 36 (29.3\%) were female. The mean age was $25.65 \pm 3.37$ (range, 18 -35) years with the majority of donors (85.4\%) between 20 and 29 years of age. Based on the CTA findings and decision of transplantation committee (a nephrologist, a urologist, and a transplant surgeon), 99 subjects (80.5\%) underwent left nephrectomy and 24 subjects (19.5\%) underwent right nephrectomy.

The image quality was 1 in 9 subjects and 2 in 114 subjects. The mean diameter of the aorta at the site of the main renal artery branching was $1.45 \pm 0.22 \mathrm{~cm}$. The kidney length, width and APD are presented in Table 1 . There was no significant difference between the parameters measured by MDCT and surgery. Samples of normal MDCT are shown in Figure 1. Furthermore, the kidney length, width and anteroposterior diameter on MDCT had direct linear correlations with intra-operative measurements $(\mathrm{P}$ $<0.001$ ) (Figure $2 \mathrm{~A}-2 \mathrm{C}$ ).

Table 1. Comparison of MDCTA Findings with Surgical Findings in Kidney Donors on the Nephrectomized Side ${ }^{a}$

\begin{tabular}{lccc}
\hline & MDCTA findings & Surgical findings & P value \\
\hline $\begin{array}{l}\text { Renal artery } \\
\text { distance, } \mathbf{c m}\end{array}$ & $3.2 \pm 1.0$ & $3.1 \pm 1.0$ & 0.625 \\
$\begin{array}{l}\text { Renal artery } \\
\text { diameter, cm }\end{array}$ & $0.5 \pm 0.4$ & $0.6 \pm 0.1$ & 0.076 \\
\hline Kidney & $10.4 \pm 1.1$ & $10.3 \pm 1.0$ & 0.823 \\
\hline \multicolumn{1}{c}{ Length, cm } & $5.6 \pm 0.8$ & $5.4 \pm 0.9$ & 0.929 \\
\hline \multicolumn{1}{c}{ Width, cm } & $4.8 \pm 0.6$ & $4.4 \pm 0.9$ & 0.959 \\
\hline \multicolumn{1}{c}{ APD, cm } & & & \\
\hline
\end{tabular}

Abbreviations: APD, anterioposterior diameter; MDCTA, multi-detector computed tomographic angiography, SD, standard deviation.

${ }^{\mathrm{a}}$ Values are expressed as mean $\pm \mathrm{SD}$.
The length and diameter of the main renal artery are shown in Table 1. No significant difference was present between the MDCT and surgery findings. There were direct linear correlations between the main renal arterial length and the diameter on the preoperative MDCT with their respective intra-operative measurements $(\mathrm{P}<0.001)$ (Figures $3 \mathrm{~A}$ and $3 \mathrm{~B}$ ). Eight (6.50\%) kidneys had one accessory artery on MDCT. All of the accessory arteries were polar, six to the upper pole and two to the lower pole (a case is shown in Figure 4A). MDCT identified all of these eight accessory arteries, with sensitivity, specificity, positive and negative predictive values of $100 \%$. Out of the 123 kidneys, early branching of the renal arteries was seen in 29 (23.57\%) of the main renal arteries in MDCT (a case is shown in Figure 4B). These findings were confirmed during surgery with sensitivity, specificity, positive and negative predictive values of $100 \%$. In case of the lengths and diameters of the renal artery, there is no difference between the values reported by the two readers $(\mathrm{P}=0.73$ and 0.88$)$. Also, the transplant surgeons reported similar lengths and diameters for the renal artery $(\mathrm{P}=0.71$ and 0.80$)$.

During surgery, 18 minor venous anomalies were identified in 17 (13.82\%) kidneys, including prominent gonadal veins draining into the renal vein in nine cases, prominent lumbar veins draining into the renal vein in four cases, small renal venous branches draining into the gonadal vein in three cases and a small renal venous branch draining into the lumbar vein in one case. All of these minor venous anomalies had also been identified by MDCT. Therefore, MDCT had 100\% sensitivity, specificity, positive and negative predictive values in the diagnosis of minor renal venous anomalies. Venous bifurcation was another studied aspect of venous anatomy that was assessed. MDCT reported six (4.87\%) venous bifurcations in main renal veins, while intra-operative evaluations revealed seven venous bifurcations in the main renal veins of seven kidneys. Therefore, one venous bifurcation was missed by MDCT, resulting in $85.71 \%$ sensitivity, $100 \%$ specificity, $100 \%$ positive predictive value and $99.14 \%$ negative predictive value in the diagnosis of venous bifurcation by MDCT. This variation was recognized on the retrospective analysis of images. With the exception of one patient who had ureteral duplication, none of the other studied cases had variation in the urinary collecting system.

Almost perfect agreement was shown between the two image analyzers regarding MDCT findings for arterial $(\kappa=$ $0.952)$, venous $(\kappa=0.911)$, and urinary collecting systems variations $(\kappa=0.958)$. 

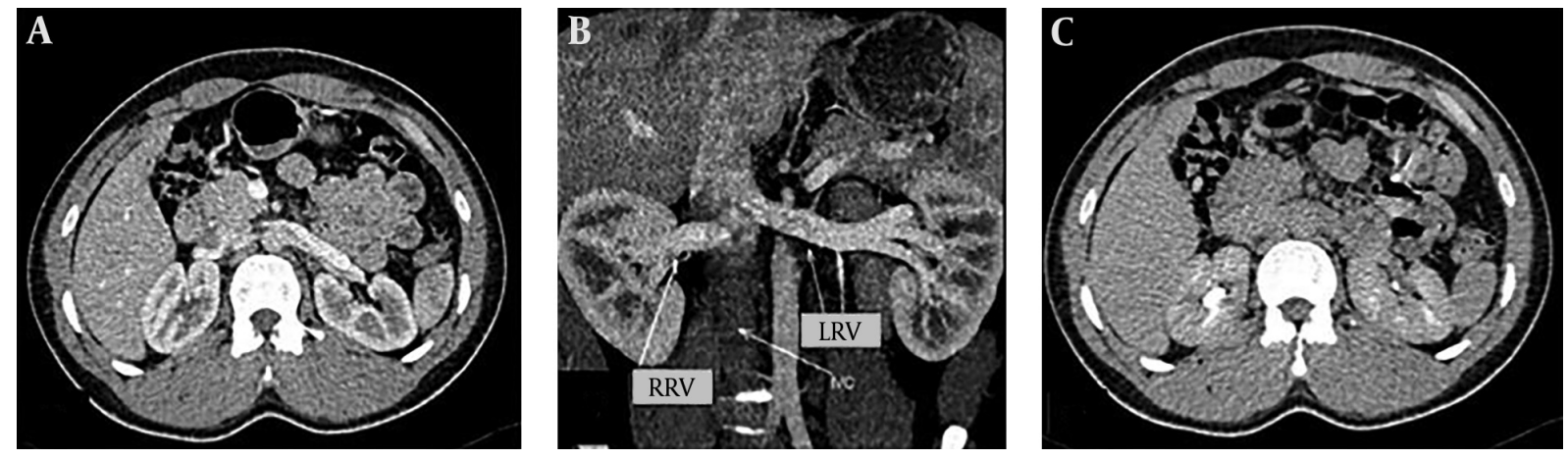

Figure 1. A normal multi detector computed tomography (MDCT) in two different phases; A, Corticomedullary phase. This phase is defined with distinct enhancement of the cortical part due to contrast media accumulation $35-40$ s after contrast injection; B, Nephrogenic phase. A coronal reconstruction of computed tomographic angiography (CTA), which indicates a clear distinction between the cortex and medulla beside homogeneous enhancement of renal veins; C, Excretory phase. This phase occurs 10 - 15 min after contrast injection, which is indicated by excretion of contrast media in renal pelvis.

A

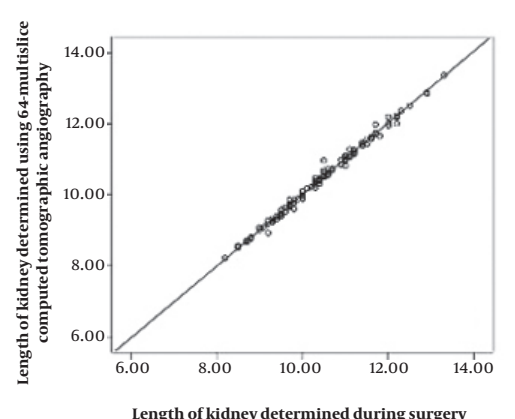

B

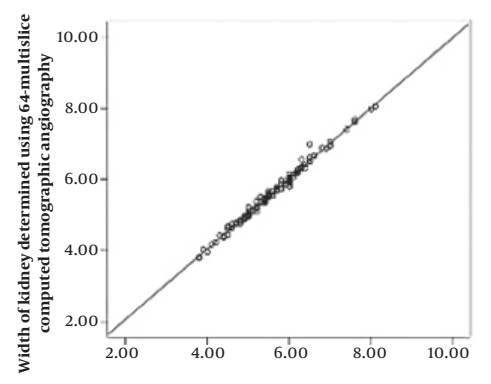

Width of kidney determined during surgery
C

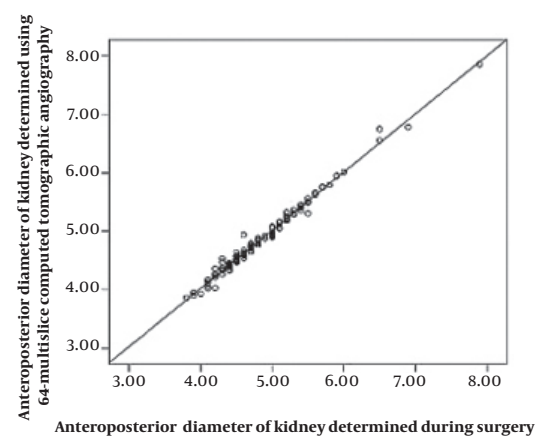

Figure 2. Scatter plots between preoperative 64-multislice computed tomographic angiography and their corresponding intraoperative surgical findings: A, Kidney length (Pearson correlation coefficient $[\mathrm{r}]=+0.997, \mathrm{P}<0.001)$; $\mathrm{B}$, Width $(\mathrm{r}=+0.995, \mathrm{P}<0.001)$ and $\mathrm{C}$, Anteroposterior diameter $(\mathrm{APD})(\mathrm{r}=+0.994, \mathrm{P}<0.001)$.

\section{Discussion}

Potential living related kidney donors require comprehensive preoperative evaluations including clinical, laboratory and radiological evaluation. The anatomic information is an important piece of the gathered data $(4,9)$. Although the conventional catheter angiography remains the gold standard for delineating renal vasculature, it is invasive and costly (10-12). MRA is an acceptable alternative noninvasive imaging modality, but MRA imaging is not sensitive for detection of urolithiasis, and its spatial resolution is inferior to MDCT. Less common availability and higher cost are other limitations of MRA imaging $(13,14)$.

The rapid evolution of CT technology allows for higher slice numbers, shorter image acquisition times, reduced tube heating, lower x-ray radiation, better collimation, and improved spatial resolution when it is compared to other single-detector helical CT scans (15). MDCT scanners are powerful modalities for angiographic investigation because they cover a larger anatomic region, the arteries have increased enhancement using contrast media, higher longitudinal spatial resolution and a more sensitive depiction and detail of the renal vascular system. In pre-operative evaluation of living kidney donors, the larger volume of coverage is important due to the fact that accessory renal arteries sometimes arise from common iliac arteries or distal abdominal aorta. Nowadays, MDCT has been known as an alternative noninvasive imaging modality to catheter renal angiography to inspect renal vascular anatomy and variations (16-23).

Accessory renal arteries were seen in $6.50 \%$, early branching of the renal artery in $23.57 \%$, and renal vein anomalies in $13.82 \%$ of the donor kidneys in the present study. According to the literature, studies have showed that the incidence of accessory renal arteries, early branching, and venous anomalies are $25 \%-42 \%, 7 \%-21 \%$, and $7 \%$ - 
A

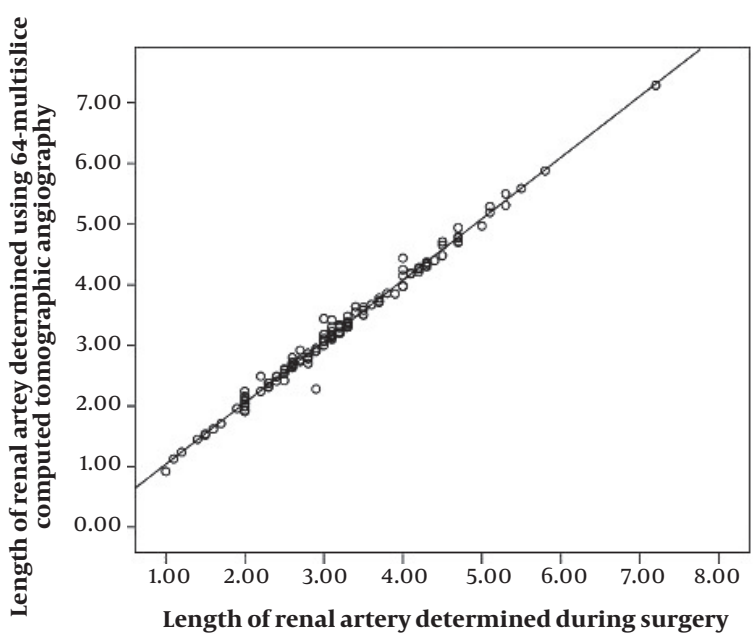

B

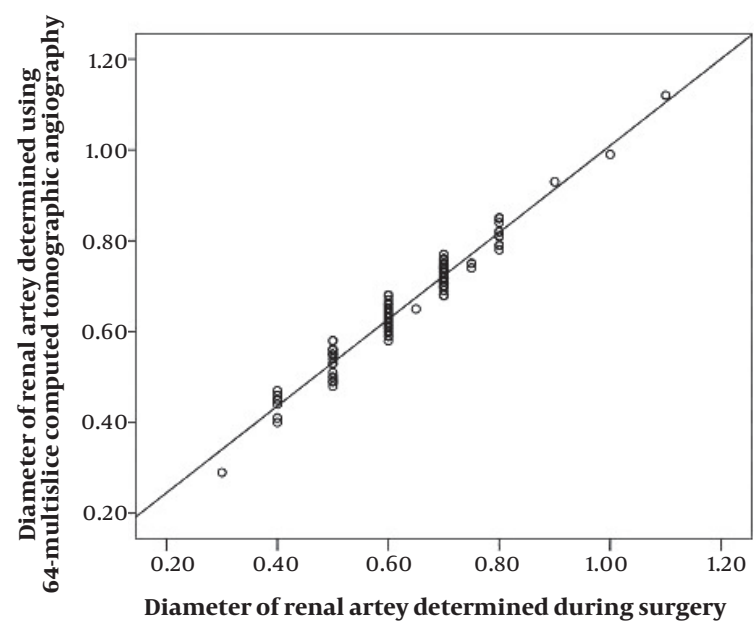

Figure 3. Scatter plots between preoperative 64-multislice computed tomographic angiography and their corresponding intraoperative surgical findings: A, Main renal arterial length (Pearson correlation coefficient $[\mathrm{r}]=+0.995, \mathrm{P}<0.001)$; $\mathrm{B}$, Main renal arterial diameter $(\mathrm{r}=+0.975, \mathrm{P}<0.001)$.
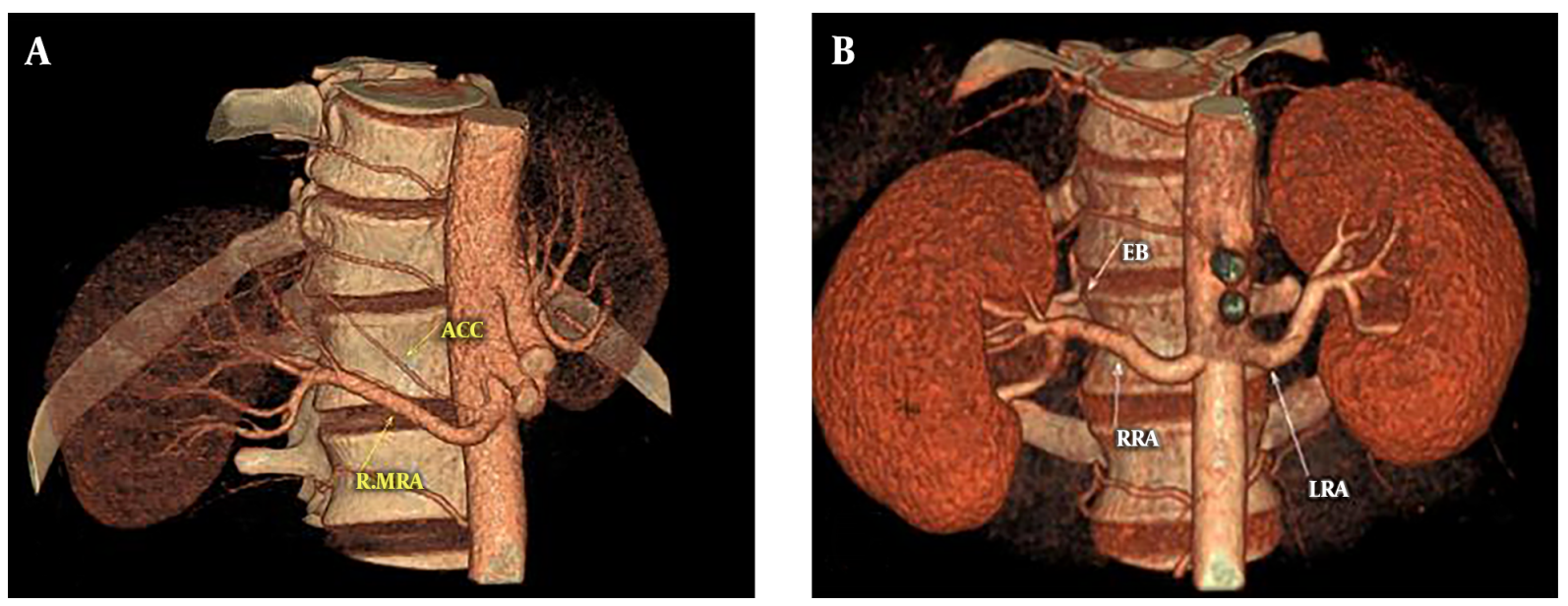

Figure 4. A case of renal artery early branching and accessory renal artery. A, Three dimensional (3D) reconstruction of computed tomographic angiography (CTA) shows an accessory right renal artery; B, 3D reconstruction of CTA indicating right renal artery early branching (RRA: right renal artery; LRB: left renal artery; EB: early branching).

$13 \%$, respectively $(10,18,24-28)$. With the exception of accessory renal arteries, prevalence of other parameters were in the reported range. The incidence of arterial anomalies is consistent with previous reports, including a large series from Johns Hopkins (29). The donor selection criteria and the side of nephrectomy could explain such differences. It has been shown that the renal arterial pattern is different between the left and right sides (30).

The reported accuracy of one-channel CT angiography in detecting renal venous anatomy, early branching, and accessory arteries varies from 78\% - 98\%, 89\% - 99\%, and 90\% - $99 \%$, respectively $(10,11,24,25,31,32)$. In primary studies on early versions of MDCT, the accuracy of detecting accessory arteries, early branching, and renal vein anomalies were $89 \%-97 \%$, 93\% - 97\%, and 96\% - 100\%, respectively (18) and were not significantly different from those of a single slice MDCT.

Studies on the application of MDCT in diagnosing an accessory renal artery have reported 80\%, 99\%, 97\% and 94\% sensitivity, specificity, positive and negative predictive val- 
ues, respectively $(18,19,33-37)$. In comparison to the present study, the reported sensitivity, specificity, positive and negative predictive values were lower or very close to those reported in the literature. Recent retrospective and prospective studies on 50 - 104 living kidney donors using 16-slice and 64 -slice MDCT showed $100 \%$ sensitivity in the diagnosis of renal accessory artery $(28,38,39)$, similar to the results of the present study.

MRA, in revealing arterial anomalies, had a sensitivity, specificity and accuracy of $89 \%, 94 \%$, and $91 \%$, respectively. In spite of the relatively small study population in some studies (15-21 donors for whom surgical correlations were available), authors reported a high sensitivity of MRA (90\% - 100\%) for identifying renal arteries in living kidney donors $(6,26,40,41)$. Gadolinium-enhanced MRA for evaluation of accessory arteries has been shown to have a sensitivity of $89 \%$, specificity of $94 \%$, and accuracy of $91 \%$ (13). In the present study, the sensitivity and specificity of 64 MDCT were higher than those of the MRA and Gadoliniumenhanced MRA. This difference could be attributed to the higher spatial resolution of MDCT.

The performance of MDCT in the current study for sensitivity, specificity, positive and negative predictive values of early branching were higher than previously reported data (95\% sensitivity, $98 \%$ specificity, $87 \%$ positive and $99 \%$ negative predictive values) $(18,19,33-36)$. These values are not significantly different from previously reported results using MDCT with fewer slices. Janoff et al. (37) have also reported that the length, width and oblique thickness, and the volume of the kidneys on MDCT were highly correlated $(\mathrm{P}<0.001)$ with intra-operative measurements.

Systematic review of the prevalence of venous anomalies shows 15 to $30 \%$ variation in the renal main vein (42). The present study demonstrated $21.13 \%$ variation in the main renal vein, which is within the previously reported range. The wide range of main renal vein variation might be due to the strict exclusion criteria for kidney donation. Multiple studies have reported different results for accuracy of MDCT in diagnosing venous anomalies. Most of the studies showed sensitivity, specificity, positive and negative predictive values of $85,99,94$, and $98 \%$, respectively (18, 19,33-36). The results of the present study were higher than previous studies with the exception of a recent prospective study (43) on 238 subjects that reported $92.4 \%$ accuracy for MDCT in assessing the renal vein compared to the intra-operative measurements. The lower performance in detecting venous structures could be attributed to the timing of contrast bolus injection.

Although the use of MDCT to evaluate renal donors is attractive, we should be aware of the disadvantages of this modality to prevent potential interpretive surgical catastrophes and difficulties. Precision in timing of image acquisition using bolus-tracking software is essential to prevent sub-optimal vascular enhancement (15). Lower thoracic aorta to the common iliac arteries is where the accessory renal artery arise. So, an insufficient scan region can limit the detection of accessory arteries deriving from the common iliac arteries or the lower thoracic aorta (44). The errors in interpretation could occur due to inadequate attention to transverse images $(34,44,45)$. These errors include small capsular or adrenal branch mistaken for a prehilar renal artery branch, and a prominent lumbar vein joining the left renal vein mistaken for a circum-aortic left renal vein $(25,42)$.

At the end of the study, open surgical comparison seems to provide better results than laparoscopic procedures, based on the Canadian study that showed a lower prediction rate for pre-laparoscopic MDCT evaluation and accurate prediction of arterial supply in 50 cases compared to surgical findings (46). As limitations of this study, all cases with MDCT findings of major accessory artery, primary renal artery branching, more than one accessory artery, major venous anomalies and poor diagnostic quality CT were excluded from this study. Nevertheless, the final population exactly reflects the subjects who were chosen for donation based on guidelines. Furthermore, these exclusions do not devalue this study's findings, as we were looking into the accuracy of MDCT for evaluation of kidney donors. We suggest a study with a larger sample size that would include MDCT, MRA, and conventional angiography (a few recent studies have showed MDCT may overestimate the degree of stenosis), with the open/laparoscopic surgery results as the gold standards. Considering the new 60 and $70 \mathrm{kVp}$ CT scanners, it would be beneficial to find the lowest $\mathrm{mA}$ and $\mathrm{KV}$ settings at which reliable readings can be obtained. This will ensure that the donors will receive the minimum $\mathrm{x}$-ray dose without compromising the accuracy and precision of the results. An inherent limitation of the study is that donors with variant renal vascular or collecting system anatomy did not undergo nephrectomy. CT findings in these patients were therefore not validated at surgery.

In conclusion, MDCT is shown to be accurate for detecting vascular and urinary collecting system, and kidney characteristics and anomalies, provides anatomic information necessary for open and/or laparoscopic nephrectomy in living donors and can provide a non-invasive, precise preoperative assessment of living kidney donor candidates in a single study. 


\section{Acknowledgments}

The scientific guarantor of this publication is Dr. Mohammad Kazem Tarzamni. We would also like to thank Dr. Javad Rashid, TUMS, for sharing his pearls of wisdom with us during the course of this research. One of the authors has significant statistical expertise. Institutional review board (TUMS research department) approval was obtained.

\section{Footnotes}

Authors' Contributions: Study concept and design: Nariman Nezami, Mohammad Naghavi-Behzad, Mohammad Khalid Mojadidi, and Reza Piri; acquisition of data: Nariman Nezami, Mohammad Naghavi-Behzad, and Behzad Salari; analysis and interpretation of data: Behzad Salari, Mohammad Khalid Mojadidi, Reza Piri, and Mohammad Kazem Tarzamni; drafting of the manuscript: Reza Piri, Sona Ghorashi, Mohammad kazem Tarzamni, and Bijan Bijan; data acquisition: Mohammad NaghaviBehzad, Behzad Salari, and Reza Piri; critical revision of the manuscript for important intellectual content: Steve Hool, Reza Piri, Sona Ghorashi, and Mohammad Kazem Tarzamni; statistical analysis: Behzad Salari, Mohammad Khalid Mojadidi, Reza Piri, Mohammad kazem Tarzamni, and Steve Hool; administrative, technical, and material support: Nariman Nezami, and Mohammad NaghaviBehzad; study supervision: Nariman Nezami, Steve Hool, and Reza Piri.

Conflict of Interests: The authors of this manuscript declare no relationships with any companies whose products or services may be related to the subject matter of the article.

Financial Disclosure: None Declared.

Funding/Support: This study was funded by drug applied research center of Tabriz University of Medical Sciences, Tabriz-Iran.

\section{References}

1. Arevalo Perez J, Gragera Torres F, Marin Toribio A, Koren Fernandez L, Hayoun C, Daimiel Naranjo I. Angio CT assessment of anatomical variants in renal vasculature: its importance in the living donor. Insights Imaging. 2013;4(2):199-211. doi: 10.1007/s13244-012-0217-5. [PubMed: 23355302]. [PubMed Central: PMC3609954].

2. Flechner SM, Sandler CM, Houston GK, Van Buren CT, Lorber MI, Kahan BD. 100 living-related kidney donor evaluations using digital subtraction angiography.Transplantation.1985;40(6):675-8. [PubMed: 3907042].

3. Spring DB, Salvatierra O Jr, Palubinskas AJ, Amend WJ Jr, Vincenti FG, Feduska NJ. Results and significance of angiography in potential kidney donors. Radiology. 1979;133(1):45-7. doi: 10.1148/133.1.45. [PubMed: 382250].
4. Walker TG, Geller SC, Delmonico FL, Waltman AC, Athanasoulis CA. Donor renal angiography: its influence on the decision to use the right or left kidney. AJR Am J Roentgenol. 1988;151(6):1149-51. doi: 10.2214/ajr.151.6.1149. [PubMed: 3055890].

5. Watarai Y, Kubo K, Hirano T, Togashi M, Ohashi N, Usuki T, et al. Intravenous digital subtraction angiography and helical computed tomography in evaluation of living renal donors. Int J Urol. 2001;8(8):417-22. [PubMed: 11555005].

6. Buzzas GR, Shield CF 3rd, Pay NT, Neuman MJ, Smith JL. Use of gadolinium-enhanced, ultrafast, three-dimensional, spoiled gradient-echo magnetic resonance angiography in the preoperative evaluation of living renal allograft donors. Transplantation. 1997;64(12):1734-7. [PubMed: 9422412].

7. Chu C, Young N, Lau H. Comparison of spiral CT angiography with conventional digital subtraction angiography in the evaluation of renal transplant donors: a pilot study. Australas Radiol. 2001;45(2):11822. [PubMed: 11380353].

8. Tunaci A, Yekeler E. Multidetector row CT of the kidneys. Eur J Radiol. 2004;52(1):56-66. doi: 10.1016/j.ejrad.2004.03.033. [PubMed: 15380847].

9. Derauf B, Goldberg ME. Angiographic assessment of potential renal transplant donors. Radiol Clin North Am. 1987;25(2):261-5. [PubMed: 3547473].

10. Cochran ST, Krasny RM, Danovitch GM, Rajfer J, Barbaric ZM, Wilkinson A, et al. Helical CT angiography for examination of living renal donors. AJR Am J Roentgenol. 1997;168(6):1569-73. doi: 10.2214/ajr.168.6.9168727. [PubMed: 9168727].

11. Pozniak MA, Balison DJ, Lee FT Jr, Tambeaux RH, Uehling DT, Moon TD. CT angiography of potential renal transplant donors. Radiographics. 1998;18(3):565-87. doi: 10.1148/radiographics.18.3.9599383. [PubMed: 9599383].

12. Slakey DP, Florman S, Lovretich J, Zarifian AA, Cheng SS. Utility of CT angiography for evaluation of living kidney donors. Clin Transplant. 1999;13(1 Pt 2):104-7. [PubMed: 10081645].

13. Jha RC, Korangy SJ, Ascher SM, Takahama J, Kuo PC, Johnson LB. MR angiography and preoperative evaluation for laparoscopic donor nephrectomy. AJR Am J Roentgenol. 2002;178(6):1489-95. doi: 10.2214/ajr.178.6.1781489. [PubMed: 12034626].

14. Kim T, Murakami T, Takahashi S, Hori M, Takahara S, Ichimaru N, et al. Evaluation of renal arteries in living renal donors: comparison between MDCT angiography and gadolinium-enhanced 3D MR angiography. Radiat Med. 2006;24(9):617-24. doi:10.1007/s11604-006-0080-8. [PubMed: 17111270].

15. Rydberg J, Liang Y, Teague SD. Fundamentals of multichannel CT. Radiol Clin North Am. 2003;41(3):465-74. [PubMed: 12797600].

16. Holden A, Smith A, Dukes P, Pilmore H, Yasutomi M. Assessment of 100 live potential renal donors for laparoscopic nephrectomy with multidetector row helical CT. Radiology. 2005;237(3):973-80. doi: 10.1148/radiol.2373041303. [PubMed: 16304115].

17. Kapoor A, Kapoor A, Mahajan G, Singh A, Sarin P. Multispiral computed tomographic angiography of renal arteries of live potential renal donors: a review of 118 cases. Transplantation. 2004;77(10):1535-9. [PubMed:15239617].

18. Kawamoto S, Montgomery RA, Lawler LP, Horton KM, Fishman EK. Multidetector CT angiography for preoperative evaluation of living laparoscopic kidney donors. AJR Am J Roentgenol. 2003;180(6):1633-8. doi: 10.2214/ajr.180.6.1801633. [PubMed: 12760934].

19. Kim JK, Park SY, Kim HJ, Kim CS, Ahn HJ, Ahn TY, et al. Living donor kidneys: usefulness of multi-detector row CT for comprehensive evaluation. Radiology. 2003;229(3):869-76. doi: 10.1148/radiol.2293021098. [PubMed: 14593192]. 
20. Raman SS, Pojchamarnwiputh S, Muangsomboon K, Schulam PG, Gritsch HA, Lu DS. Utility of 16-MDCT angiography for comprehensive preoperative vascular evaluation of laparoscopic renal donors. AJR Am J Roentgenol. 2006;186(6):1630-8. doi: 10.2214/AJR.05.0983. [PubMed: 16714653].

21. Raman SS, Pojchamarnwiputh S, Muangsomboon K, Schulam PG, Gritsch HA, Lu DS. Surgically relevant normal and variant renal parenchymal and vascular anatomy in preoperative 16-MDCT evaluation of potential laparoscopic renal donors. AJR Am J Roentgenol. 2007;188(1):105-14. doi:10.2214/AJR.05.1002. [PubMed: 17179352].

22. Rastogi N, Sahani DV, Blake MA, Ko DC, Mueller PR. Evaluation of living renal donors: accuracy of three-dimensional 16-section CT. Radiology. 2006;240(1):136-44. doi: 10.1148/radiol.2401050780. [PubMed: 16720871].

23. Rydberg J, Kopecky KK, Tann M, Persohn SA, Leapman SB, Filo RS, et al. Evaluation of prospective living renal donors for laparoscopic nephrectomy with multisection CT: the marriage of minimally invasive imaging with minimally invasive surgery. Radiographics. 2001;21 Spec No:S223-36. doi: 10.1148/radiographics.21.suppl_1.g01oc10s223. [PubMed: 11598259].

24. Rubin GD, Alfrey EJ, Dake MD, Semba CP, Sommer FG, Kuo PC, et al. Assessment of living renal donors with spiral CT. Radiology.1995;195(2):457-62. doi:10.1148/radiology.195.2.7724766.[PubMed: $7724766]$.

25. Platt JF, Ellis JH, Korobkin M, Reige K. Helical CT evaluation of potential kidney donors: findings in 154 subjects. AJR Am J Roentgenol. 1997;169(5):1325-30. doi: 10.2214/ajr.169.5.9353451. [PubMed: 9353451].

26. Rankin SC, Jan W, Koffman CG. Noninvasive imaging of living related kidney donors: evaluation with CT angiography and gadoliniumenhanced MR angiography. AJR Am J Roentgenol. 2001;177(2):349-55. doi:10.2214/ajr.177.2.1770349. [PubMed:11461860].

27. Dachman AH, Newmark GM, Mitchell MT, Woodle ES. Helical CT examination of potential kidney donors. AJR Am J Roentgenol. 1998;171(1):193-200. doi: 10.2214/ajr.171.1.9648788. [PubMed: 9648788].

28. Zhang J, Hu X, Wang W, Li X, Hang Y, Zhang X. Role of multidetector-row computed tomography in evaluation of living renal donors. Transplant Proc. 2010;42(9):3433-6. doi: 10.1016/j.transproceed.2010.06.002. [PubMed: 21094791].

29. Chu LC, Sheth S, Segev DL, Montgomery RA, Fishman EK. Role of MDCT angiography in selection and presurgical planning of potential renal donors. AJR Am J Roentgenol. 2012;199(5):1035-41. doi: 10.2214/AJR.11.8058. [PubMed: 23096176].

30. Tarzamni MK, Nezami N, Rashid RJ, Argani H, Hajealioghli P, Ghorashi $S$. Anatomical differences in the right and left renal arterial patterns. Folia Morphol (Warsz). 2008;67(2):104-10. [PubMed:18521808].

31. Smith PA, Ratner LE, Lynch FC, Corl FM, Fishman EK. Role of CT angiography in the preoperative evaluation for laparoscopic nephrectomy. Radiographics. 1998;18(3):589-601. doi: 10.1148/radiographics.18.3.9599384. [PubMed: 9599384].

32. Smith PA, Fishman EK. Three-dimensional CT angiography: renal applications. Semin Ultrasound CT MR. 1998;19(5):413-24. [PubMed: 9800251].

33. Laugharne M, Haslam E, Archer L, Jones L, Mitchell D, Loveday E, et al. Multidetector CT angiography in live donor renal transplantation: experience from 156 consecutive cases at a single centre. Transpl Int. 2007;20(2):156-66. doi: 10.1111/j.1432-2277.2006.00417.x. [PubMed:
17239024].

34. Sahani DV, Rastogi N, Greenfield AC, Kalva SP, Ko D, Saini S, et al. Multidetector row CT in evaluation of 94 living renal donors by readers with varied experience. Radiology. 2005;235(3):905-10. doi:10.1148/radiol.2353040496. [PubMed: 15833989].

35. Namasivayam S, Small WC, Kalra MK, Torres WE, Newell KA, Mittal PK. Multidetector-row CT angiography for preoperative evaluation of potential laparoscopic renal donors: how accurate are we? Clin Imag ing. 2006;30(2):120-6. doi: 10.1016/j.clinimag.2005.09.023. [PubMed: 16500543]

36. el-Diasty TA, Shokeir AA, el-Ghar ME, Gad HM, Refaie AF, el-Din AB Contrast enhanced spiral computerized tomography in live kidney donors: a single session for anatomical and functional assessment. J Urol. 2004;171(1):31-4. doi:10.1097/01.ju.0000099784.52825.8e. [PubMed: 14665837].

37. Janoff DM, Davol P, Hazzard J, Lemmers MJ, Paduch DA, Barry JM. Computerized tomography with 3-dimensional reconstruction for the evaluation of renal size and arterial anatomy in the living kidney donor. J Urol. 2004;171(1):27-30. doi: 10.1097/01.ju.0000100084.59864.8f. [PubMed: 14665836]

38. Mishra A, Ehtuish EF. The pattern of renal vessels in live related potential donors pool. A multislice computed tomography angiography review. Saudi Med J. 2006;27(6):841-4. [PubMed:16758047].

39. Turkvatan A, Akinci S, Yildiz S, Olcer T, Cumhur T. Multidetector computed tomography for preoperative evaluation of vascular anatomy in living renal donors. Surg Radiol Anat. 2009;31(4):227-35. doi: 10.1007/s00276-008-0428-0. [PubMed:18953477].

40. Bakker J, Ligtenberg G, Beek FJ, van Reedt Dortland RW, Hene RJ Preoperative evaluation of living renal donors with gadoliniumenhanced magnetic resonance angiography. Transplantation. 1999;67(8):1167-72. [PubMed: 10232569].

41. Halpern EJ, Mitchell DG, Wechsler RJ, Outwater EK, Moritz MJ, Wilson GA. Preoperative evaluation of living renal donors: comparison of CT angiography and MR angiography. Radiology. 2000;216(2):434-9. doi: 10.1148/radiology.216.2.ro0au25434. [PubMed:10924566].

42. Urban BA, Ratner LE, Fishman EK. Three-dimensional volumerendered CT angiography of the renal arteries and veins: normal anatomy, variants, and clinical applications. Radiographics. 2001;21(2):373-86. questionnaire 549-55. doi: 10.1148/radiographics.21.2.g01mr19373. [PubMed: 11259702].

43. Kim MU, Choi KH, Yang SC, Oh YT, Han WK. Prospective Evaluation of the Accuracy of MDCT Angiography for Living Kidney Donor. Korean J Urol. 2011;52(2):124-9. doi: 10.4111/kju.2011.52.2.124. [PubMed: 21379430]. [PubMed Central: PMC3045718].

44. Kawamoto S, Montgomery RA, Lawler LP, Horton KM, Fishman EK. Multi-detector row CT evaluation of living renal donors prior to laparoscopic nephrectomy. Radiographics. 2004;24(2):453-66. doi 10.1148/rg.242035104. [PubMed: 15026593].

45. Fleischmann D. Multiple detector-row CT angiography of the renal and mesenteric vessels. EurJ Radiol. 2003;45 Suppl 1:S79-87. [PubMed: 12598031].

46. Feifer AH, Fong BC, Feldman L, Fried G, Stein LA, Metrakos P, et al. Preoperative evaluation of laparoscopic living renal donors with computerized tomography and its effect on donor morbidity and graft function. Can J Urol. 2005;12(3):2713-21. [PubMed: 16011820]. 